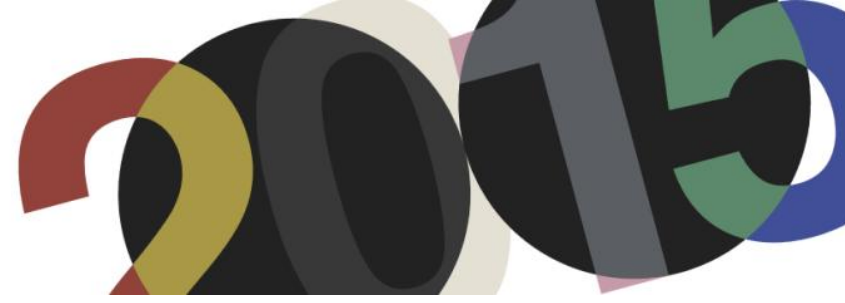

DOI: http://dx.doi.org/10.4995/LC2015.2015.638

\title{
« Histoire d'une Fenêtre ». Le Corbusier y la construcción de la mirada
}

\author{
R. Merí de la Maza, A. Díaz Segura, B. Serra Soriano \\ Escuela Superior de Enseñanzas Técnicas. Universidad CEU Cardenal Herrera. Valencia
}

\begin{abstract}
Resumen: El artículo presenta un estudio de la relación de Le Corbusier con un mecanismo constructivo y de lenguaje arquitectónico fundamental en su obra como es la ventana. Durante ese recorrido se estudian diferentes aspectos que afectan a la definición de la ventana y su relación con la arquitectura que la contiene; en especial centrados en la idea de continuidad espacial y en la disolución conceptual y física de los límites del espacio. Para ello se cruzan enfoques que van desde lo puramente conceptual hasta las relaciones que se establecen entre las soluciones constructivas y sus repercusiones visuales sobre el objeto arquitectónico. Esta breve historia de la ventana en Le Corbusier está centrada en su obra doméstica a través de una secuencia cronológica que permite tener un panorama de la evolución de este elemento en su trayectoria. Podemos ver cómo se produce la transición desde la fenêtre en longueur hasta el pan de verre aménagé, pasando por numerosas aspiraciones, configuraciones y variaciones sobre el propio tema de la mirada y el mecanismo constructivo-visual que la define.
\end{abstract}

\begin{abstract}
The article presents a study of the relationship of Le Corbusier with very a important constructive architectural mechanism in his work as the window is. During that route we study different issues affecting the definition of the window and its relationship to the architecture that contains it; in particular focusing on the idea of spatial continuity and the conceptual and physical dissolution of the limits of space. For that purpose we take different approaches ranging from the purely conceptual to the relationships established between the constructive solutions and their visual impact on the architectural object. This brief history of the Window at Le Corbusier is focused on his domestic work through a chronological sequence that allows an overview of the evolution of the element in his work. We can see how the transition occurs from the fenêtre en longueur to the pan de verre aménagé, through numerous aspirations, configurations and variations on the gaze theme and the constructive mechanism that defines it.
\end{abstract}

Palabras clave: Le Corbusier; Fenêtre; mecanismos constructivos; mirada; ventana.

Keywords: Le Corbusier; Fenêtre; constructive mechanisms; gaze; window.

\section{Introducción}

"Celui qui regarde du dehors à travers une fenêtre ouverte, ne voit jamais autant de choses que celui qui regarde une fenêtre fermée. Il n'est pas d'objet plus profond, plus mystérieux, plus fécond, plus ténébreux, plus éblouissant qu'une fenêtre éclairée d'une chandelle. Ce qu'on peut voir au soleil est toujours moins intéressant que ce qui se passe derrière une vitre ...".

La ventana es un pequeño misterio de la arquitectura, símbolo de continuidad y discontinuidad, intensa en sus variaciones ya etimológicamente hablando, con alternativas que oscilan entre el concepto de paso/perforación y el del elemento que lo cierra. El castellano y el inglés comparten raíces para sus términos con el aire como soporte conceptual (viento-wind) y su origen en el latín ventus o en el antiguo nórdico vindauga (viento-ojo) provienen ambos de la raíz indoeuropea we- (soplar). En estos casos la concepción de la ventana como perforación que permite el paso del viento ha quedado como predominante frente a la mirada, mientras que en

\footnotetext{
${ }^{1}$ Baudelaire, Charles: «Les fenêtres », Petits Poèmes en prose, édition posthume 1869.
} 
las lenguas eslavas es el término okno (ojo) el que se mantiene como primordial. A su vez en el francés (fenêtre) o el italiano (finestra), provenientes del latín feněstra, los vocablos parecen remitirnos a la condición de final de lo externo y, consecuentemente, de principio de lo interno, aunque también se especula con su origen en la raíz griega phainein que significaba igualmente mostrar. Caso aparte es el término portugués janela que se remonta a la pequeña puerta llamada en latín vulgar januella, y que tenía su origen en Iānus (Jano), dios romano de las puertas, el de las dos caras, una mirando hacia fuera y la otra hacia dentro. Esta denominación hace también referencia al objeto que cierra, pero en este caso es el propio elemento de cierre el que toma cuerpo y observa desde su posición los sucesos al tiempo dentro y fuera de la estancia.

La ventana es un tema clave en la arquitectura ya que se significa como la manera de vivir la relación entre interior y exterior, y su definición formal y tecnológica contribuye tanto como las elecciones etimológicas a una determinada percepción del mundo que nos rodea. En ese sentido, la ventana ha sido siempre un objeto de búsqueda vinculado a los paradigmas que la arquitectura pretendía. Proporción, escala, profundidad y posición revelaban las intenciones en su vinculación, o no, con el hombre como habitante del espacio.

La modernidad tuvo uno de sus principios en la posibilidad de separar los diferentes sistemas que integran el hecho arquitectónico. Una de las consecuencias de la desintegración de la unicidad de los sistemas portante, compositivo, volumétrico-formal y espacial fue la posibilidad de modificar la relación entre interior y exterior en la arquitectura. No es de extrañar pues que se convirtiese en tema recurrente de reflexión.

Estas nuevas relaciones van a afectar, evidentemente, a la percepción del exterior desde los espacios interiores, pero también a la construcción de la realidad del espacio interior en su percepción desde el exterior. En esta doble búsqueda de miradas condicionadas del espectador tendrá especial importancia la intensificación del efecto de transparencia literal percibida mayoritariamente desde el interior, pero igualmente clave será la reconstrucción fenomenológica de la realidad y los mecanismos visuales empleados para lograrla también desde el exterior del objeto construido.

En la modernidad, el límite del espacio pierde su condición de frontera para ganar la de horizonte y de esa manera se transmuta tanto la percepción del espacio arquitectónico como las reglas de definición de su límite. Hay que buscar una concreción construida para ese nuevo límite y la definición visual que lo acompaña, y esa búsqueda va a estar presente de manera especialmente intensa en la obra arquitectónica de Le Corbusier.

\section{Histoire d'une Fenêtre}

Hablar de la transformación del límite del espacio y de la construcción de la mirada en Le Corbusier es hacerlo de manera casi directa de la separación entre los diferentes sistemas de la arquitectura que apuntábamos anteriormente. Fue Le Corbusier quien entendió mejor que nadie las consecuencias implícitas de esta disociación, y desde luego fue él quien intentó postular de manera directa cuáles habían de ser sus consecuencias inmediatas en sus cinco puntos para una arquitectura nueva.

Como el propio Le Corbusier escribe "hasta la llegada del cemento armado y el hierro, para construir una casa de piedra, se abrían unas anchas zanjas en la tierra (...) luego, se subían las paredes de piedra. Se establecía un primer piso apoyado sobre los muros, después un segundo y un tercero; se abrían ventanas (...) Abrir ventanas en el muro en el cual se apoyan los pisos es una operación contradictoria; abrir unas ventanas es debilitar el muro. Había, pues, un límite entre la función de sostener los pisos y la de darles luz."2

\footnotetext{
${ }^{2}$ Jeanneret, Charles-Edouard (Le Corbusier): Precisiones, Apóstrofe, Barcelona, 1999, p. 56.
} 
La fenêtre es a la obra de Le Corbusier como los ojos a la expresión de una persona, a su mirada; nos cuenta una historia, nos da pistas sobre su carácter y sus intenciones. Libera el espacio y condiciona al usuario. Este breve recorrido por las "ventanas" de Le Corbusier está principalmente centrado en su obra doméstica, y transita a través de varias de sus obras en una secuencia cronológica que nos permite tener un cierto panorama de la evolución del elemento a lo largo de su trayectoria, sus variaciones. Durante este trayecto nuestro objetivo es desgranar y poner en relación diferentes aspectos que afectan a la definición de la ventana y su relación con la arquitectura que la contiene. En especial nos centraremos en la idea de continuidad espacial y en la permeabilidad conceptual y física de los límites del espacio. Para ello cruzaremos enfoques que irán desde lo puramente conceptual hasta las relaciones que se establecen entre las soluciones constructivas y sus repercusiones visuales sobre el objeto arquitectónico.

\subsection{Maisons Citrohan}

Las casas Citrohan nos van a servir como punto de arranque, cronológicamente hablando, para entender los mecanismos de relación entre interior y exterior de Le Corbusier. Proyectadas en su primera versión en el año 1920, suponen el corolario (al menos etimológicamente hablando) a la idea de la máquina de habitar anticipada desde las páginas de la publicación de L'Esprit Nouveau. La primera versión, implantada directamente sobre el territorio se relacionaba con él desde el interior a través de sus fachadas cortas, ya que la casa estaba direccionada y concebida como un túnel que recogía la luz por sus extremos. Su posicionamiento en la cota del suelo permitía el acceso directo a la sala desde el exterior. Este espacio a doble altura, el corazón de la casa, se relacionaba en toda su dimensión con el exterior mediante un doble ventanal que ocupaba los dos niveles inferiores de la casa. Estos ventanales venían definidos en los dibujos como una serie homogénea y continua de carpinterías verticales partidas en el punto medio de su altura. En el dibujo publicado en el primer volumen de la "Euvre" Complète, observamos como Le Corbusier coloca un elemento ligero de transición y protección solar frente a este gran ventanal que no estaba en las primeras vistas de la casa. (FLC 20707A)

La versión modificada, que se va a presentar al Salón de Otoño del año 1922, muestra ya la incorporación de otra pieza fundamental para entender la relación de las casas de Le Corbusier con el territorio, el pilotis. La relación de la sala se establece con una terraza que envuelve dos de los laterales de la casa, adelantando también en esto otro de los mecanismos de relación con el exterior que Le Corbusier va a poner habitualmente en juego.

Le Corbusier probará con dos versiones de barandilla, una metálica de elementos verticales (FLC 20710), la otra opaca y maciza (FLC 20709) que será la que finalmente adopte en la versión definitiva. En ambos dibujos se mantiene la partición de carpintería en elementos verticales iguales recogida en la propuesta original. Sin embargo en la última versión, los huecos que dan correspondencia a la pared frontal de la sala se mantienen en su configuración a doble nivel e incluso en su partición horizontal interna en el punto medio, mientras que la fenestración varía para transformarse en un menor número de series alternas de ventanas de proporción más ancha, anticipando los estudios posteriores de la casa La Roche. (FLC 20714)
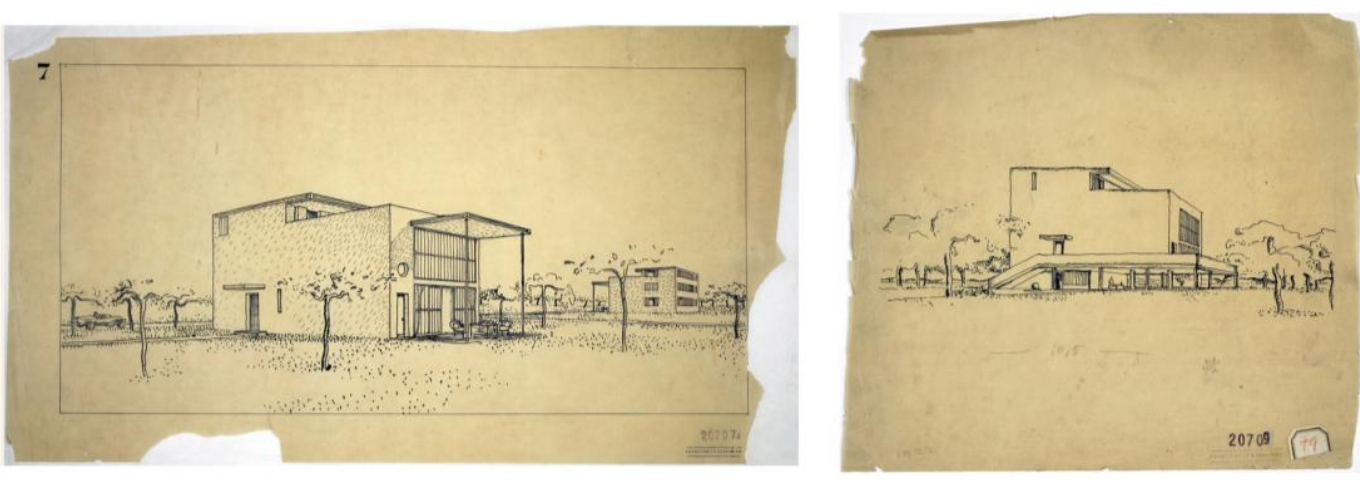


\subsection{Casa taller para Ozenfant}

A principios del siguiente año, 1923, construirá Le Corbusier la casa-estudio para su amigo y colega el pintor Amédée Ozenfant, en la que debido a las necesidades lumínicas necesarias dará un paso enorme en la disolución de la esquina. Esta labor conceptual de abrir el espacio del volumen del estudio hacia el exterior en tres de las caras del diedro conseguía apropiarse por completo de la luz y del paisaje.

Será en este mismo año cuando Le Corbusier escriba en Vers une architecture el título: "Le dehors est toujours un dedans" "3 y acompañando el capítulo aparecen una serie de bocetos de la Villa Adriana y el Foro de Pompeya en los que el horizonte y los objetos lejanos se perciben enmarcados desde el interior de los espacios.
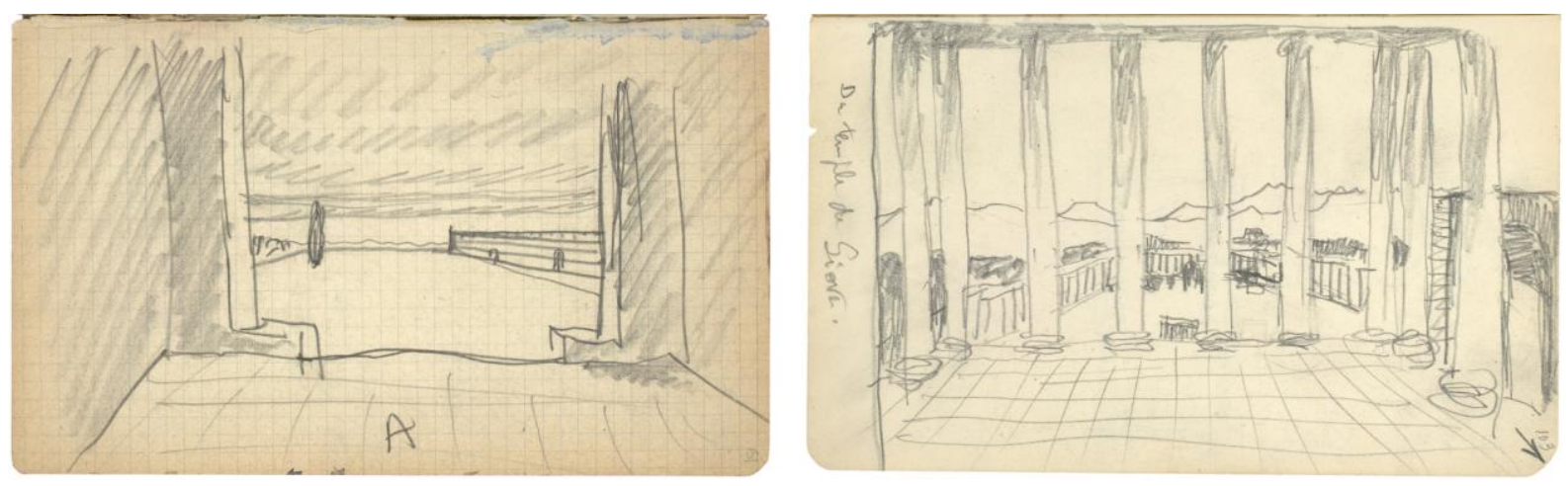

2. Bocetos de la Villa Adriana y del Foro de Pompeya del Carnet voyage d'Orient, incluidos en Vers une architecture. OFLCADAGP

La distribución de la fenestración estaba perfectamente estudiada en su composición por Le Corbusier, como se comprueba en los dibujos de los alzados previos en los que ya están presentes los trazados reguladores para su ordenación (FLC 07848 y FLC 07849), esquema que apenas sufrirá variaciones en su versión definitiva (FLC 07850). Esto se pone de manifiesto en las relaciones que se establecen entre los dos módulos de ventanas existentes en cada alzado. El tercer plano del diedro es el que conforma la fenestración del techo, en el que se ponen en relación ambas modulaciones. La imposibilidad técnica de generar un mecanismo de luz horizontal perfectamente plano al exterior llevó a la colocación de vidrios translucidos en este plano, que eliminaban desde el interior la visión de la solución técnica finalmente adoptada: dos lucernarios en diente de sierra. Su presencia caracterizaba la casa en su imagen exterior, pero se negaba desde el interior para potenciar la búsqueda de la abstracción del mecanismo diseñado para establecer la relación con el exterior en la esquina. (FLC 07824)

\footnotetext{
3 “El exterior es siempre un interior". Le Corbusier-Saugnier: Vers une architecture, Paris, éd. Crès, 1923, p. 154.
} 

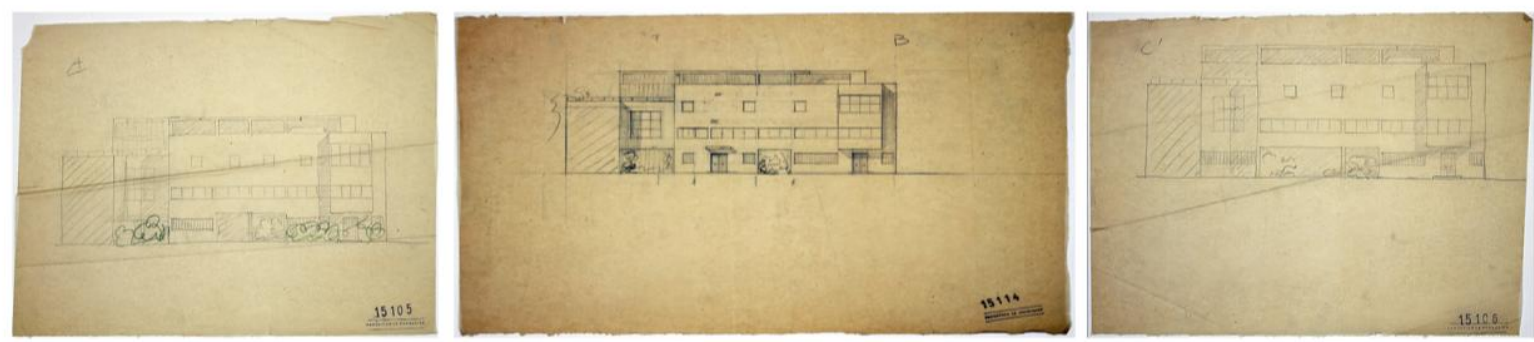

3. Casa estudio para Ozenfant. Alzados FLC 07850 y vista interior del taller. CFLC-ADAGP

La clave estriba en que todas estas operaciones se siguen realizando sobre un contenedor murario, en el cual aún no está presente la estructura como elemento autónomo disociado del espacio. La apertura frontal de las Citrohan se extiende a los planos contiguos del diedro, pero en esencia se trata de la misma disolución plana de los límites del espacio.

\subsection{Maison La Roche-Jeanneret}

Aproximadamente por las mismas fechas comienza a desarrollarse el proyecto para la villa La Roche-Jeanneret también en París. En esta casa, vamos a centrarnos en un único hueco, que es uno de los más complejos proyectados por Le Corbusier en cuanto a sus relaciones con los elementos que lo rodean. La abertura en cuestión es la superior del vestíbulo de la casa La Roche.

El espacio del hall es de por sí especialmente rico; recoge todo el sistema de recorridos de la casa; se abre en cada nivel de una manera distinta a los restantes espacios que lo circundan y queda colonizado por la presencia de la escalera, que a modo de mirador lo invade. Pero, ¿cómo se relaciona con el exterior este espacio? Un único ventanal de grandes proporciones muestra al habitante el espacio exterior de la casa, dándole, según donde se encuentre situado dentro del espacio interior, una percepción diferente de lo que ocurre fuera. Pero este elemento del que hablamos varió considerablemente desde las primeras versiones proyectadas hasta su configuración definitiva.

En las primeras propuestas nos encontramos con un hueco de proporciones cuadradas flotando en el centro del paño opaco y manteniendo una distancia de separación con los límites, tanto laterales como superior, igual al de cada uno de los tres módulos de carpintería que componen el hueco. Estos estudios varían en la configuración del elemento inferior del acceso; la versión A con una puerta centrada sobre el paño opaco (FLC 15105); la versión B completamente abierta (FLC 15114); y la versión C con un hueco horizontal en fenêtre en longueur (FLC 15106 y FLC 15190). 


\section{Casa La Roche-Jeanneret. Alzados. Versiones A, B y C. FLC 15105, FLC 15114, FLC 15106. OFLC-ADAGP}

El 22 de septiembre de 1923, en una segunda versión, el hueco crece horizontalmente, adoptando una configuración más parecida a la final, abarcando completamente los límites del paño (FLC 15274 y FLC 15275). La fenestración conserva aún la disposición de particiones cuadradas iguales repetidas en una matriz que de 3 por 3 elementos crece hasta las 3 filas por 5 columnas, apropiándose del espacio originalmente reservado para el macizo (FLC 15110), y reproduciendo una solución similar a la del taller para Ozenfant.

El 2 de octubre de ese mismo año la configuración de la fenestración va a verse modificada y aparece por primera vez el elemento inferior corrido sin particiones verticales, sobre el que gravitan las particiones superiores que también están sufriendo cambios en su modulación y distribución (FLC 15185). En este punto Le Corbusier, con la excusa de los trazados reguladores del alzado y su relación con la distribución de la carpintería, hace desaparecer nuevamente la extensión del hueco hasta los límites del paño (FLC 15109); desaparición que se verá confirmada en la primera versión de los alzados pasados a tinta en los cuales ya se aprecia claramente una distribución similar a la definitiva, pero conservando una estrechísima franja vertical maciza en ambos laterales del "'ииесо" (FLC 15207).
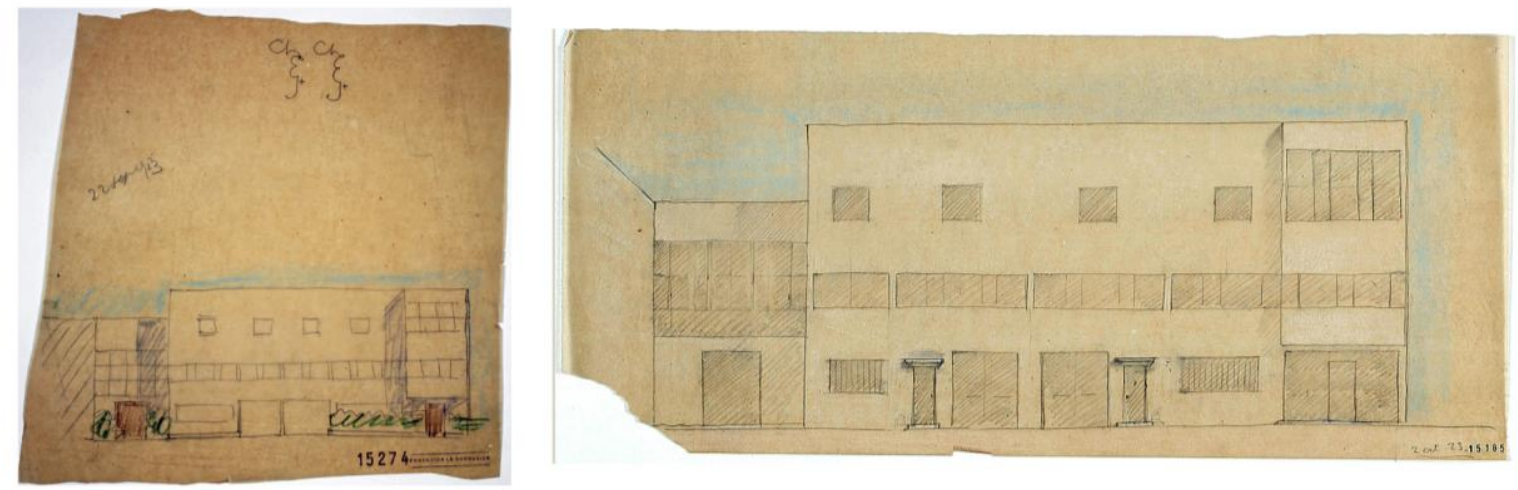

5. Casa La Roche-Jeanneret. Alzados. FLC 15274, FLC 15185. OFLC-ADAGP

La última versión recupera el ancho total del paño hasta las paredes perpendiculares al mismo, y en un primer dibujo, que Le Corbusier anula posteriormente, puede observarse cómo los travesaños horizontales que enmarcan el módulo horizontal inferior adquieren una mayor sección para resolver el problema de la transmisión de cargas de las particiones superiores (FLC 15255). La presencia de una doble línea en la parte inferior del hueco sugiere la posibilidad de un cierto desplazamiento sobre el plano vertical de la fachada, que se reproduce igualmente en el plano pasado a tinta (FLC 15208).

Veamos cómo queda configurada la versión definitiva (FLC 15232). En primer lugar nos encontramos con una pared de cristal de grandes dimensiones que se relaciona con un espacio de corredor que comunica las dos partes de la casa en planta primera. El ventanal arranca desde el suelo del corredor, ofreciendo la sensación de continuidad espacial con el exterior desde este punto, en una configuración similar a la que veíamos en la segunda versión de la casa Citrohan, pero invertida. La terraza balcón ha pasado de estar situada al exterior, a 
actuar a modo de cubierta protectora interior de la puerta de acceso, y el gran ventanal comunica con el exterior la compleja triple altura interior.

El ventanal queda dispuesto abarcando todo el ancho del espacio del hall, pero no abarca en su dimensión vertical toda la altura que dispone dicho espacio. Aquí el volumen es compacto y cerrado, y no existe plano horizontal de techo que se prolongue hacia el exterior. De esta manera, nos encontramos con que la definición superior del ventanal está establecida por un plano blanco que cruza superiormente el espacio, y que apoya tangentemente en los dos planos perpendiculares que han quedado interrumpidos para configurar las barandillas de los dos espacios superiores vinculados al mismo, y que se prolongan en los planos exteriores para enfatizar aún más la continuidad espacial con el exterior. Esta relación de tangencias y apoyos tan extremadamente bien estudiada desmaterializa, desde la percepción interior, la disposición del ventanal como hueco, convirtiéndolo en pura ausencia de plano, percepción que se va a ver incrementada por su división y el tratamiento de las carpinterías. A propósito de esta relación escribe Bruno Reichlin: "La grande finestra sullo square va da parete a parete e non ha stipi; l'architrave poggia direttamente sul parapetto della biblioteca. Architrave, parapetto e finestra sono 'ridotti' alla loro più semplice espressione geometrica: sone delle lastre parallelepipede giustapposte" ${ }^{\text {. }}$.
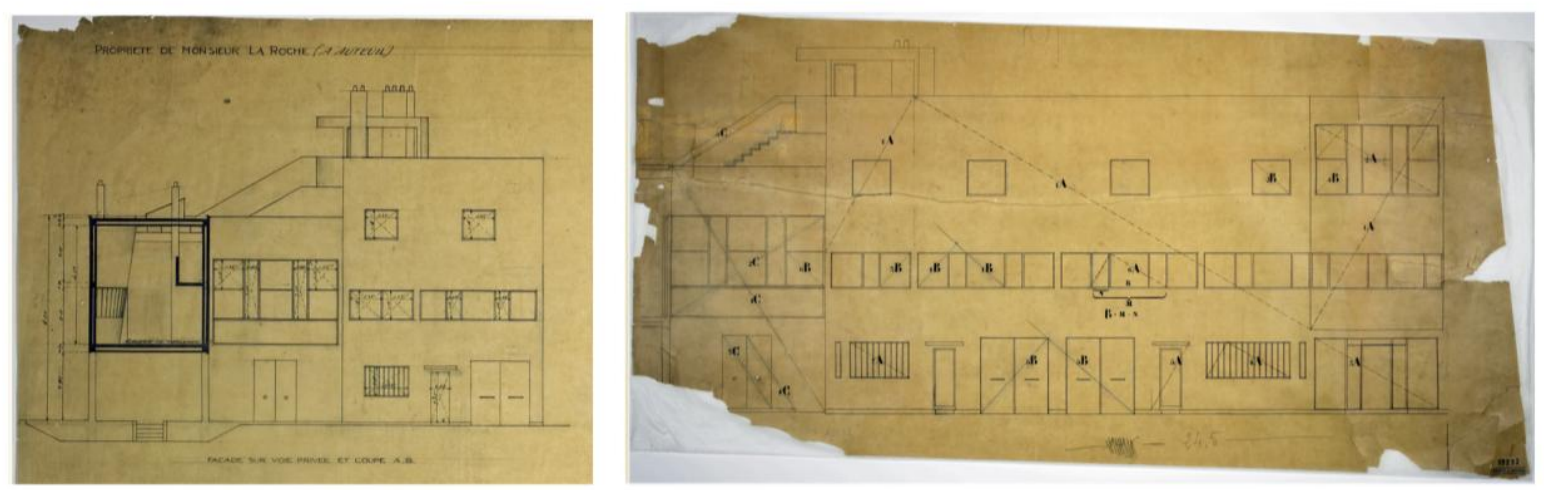

6. Casa La Roche-Jeanneret. Alzados. FLC 15207 (detalle) y FLC 15232. OFLC-ADAGP

El ventanal queda conformado por dos bandas horizontales diferenciadas, que están separadas por el elemento de mayor sección de la carpintería, un perfil en U dispuesto hacia el interior. La banda inferior recoge la altura del alféizar y los dos huecos menores situados junto a ella en los planos perpendiculares. Esta parte tiene vocación de ser continua, dando respuesta invertida al macizo formado por la barandilla interior de la pasarela. Pero la luz es muy grande para que el travesaño horizontal, a pesar de su mayor sección, sea capaz de soportar la sección de ventanal que queda por encima. Así pues, Le Corbusier coloca dos machones verticales que dividen esa banda inferior en tres partes iguales, pero lo hace con los elementos de menor sección visual de todo el conjunto de la carpintería, casi hasta hacerlos desaparecer en el exterior. Estos diminutos parteluces de acero se refuerzan en su cabeza, al interior, con unas pequeñas cartelas que aseguran la transición en profundidad con el travesaño principal.

La división a tercios la franja establece a su vez varias relaciones. La primera y más evidente con la parte superior de la carpintería; en este caso la relación es de no coincidencia o de discontinuidad, quedando centrados con respecto de las dos particiones menores superiores, que a su vez son los que recorren el resto del ventanal en

\footnotetext{
${ }^{4}$ Reichlin, Bruno: "Le Corbusier vs De Stijl: verso la scomposizione in piani della compagine parietale. La Villa La Roche a Auteuil, 1923-1925", en: Dalla "soluzione elegante" all""edificio aperto". Scritti attorno ad alcune opere di Le Corbusier, Mendrisio Academy Press / SilvanaEditoriale, Mendrisio, 2013, p. 65.
} 
toda su altura sin interrupción horizontal. Con todo ello, Le Corbusier está marcando la falta de continuidad en los elementos verticales de la carpintería, que no pueden realizar la transmisión directa de las cargas, tensionando visualmente el conjunto y dándole mayor énfasis si cabe a la vocación de continuidad de la pieza de vidrio inferior. Así pues, el travesaño horizontal actúa como barandilla virtual, pero con el peso visualmente invertido al quedar por encima de ella, dando además pie a otra relación visual que se establece con la barandilla metálica interior colocada sobre el macizo opaco de la pasarela hacia la triple altura. Este juego de elementos pesados y ligeros invertidos a ambos lados de la pasarela va a generar una tensión diagonal en el espectador que le lleva a concentrar su atención en la conexión visual desde el volumen vacío superior al interior con el plano de suelo situado al exterior.

Para terminar con el conjunto de correspondencias nos encontramos con el travesaño horizontal que divide a la mitad los tres elementos verticales mayores de la parte superior del ventanal, justo en el punto de concurrencia del límite superior de los dos huecos situados en las paredes perpendiculares, y por supuesto con el dintel de los accesos a la pasarela desde cada uno de sus extremos; tensión de líneas que se va prolongar en el resto de elementos situados en el vestíbulo, ya más lejos del ventanal.
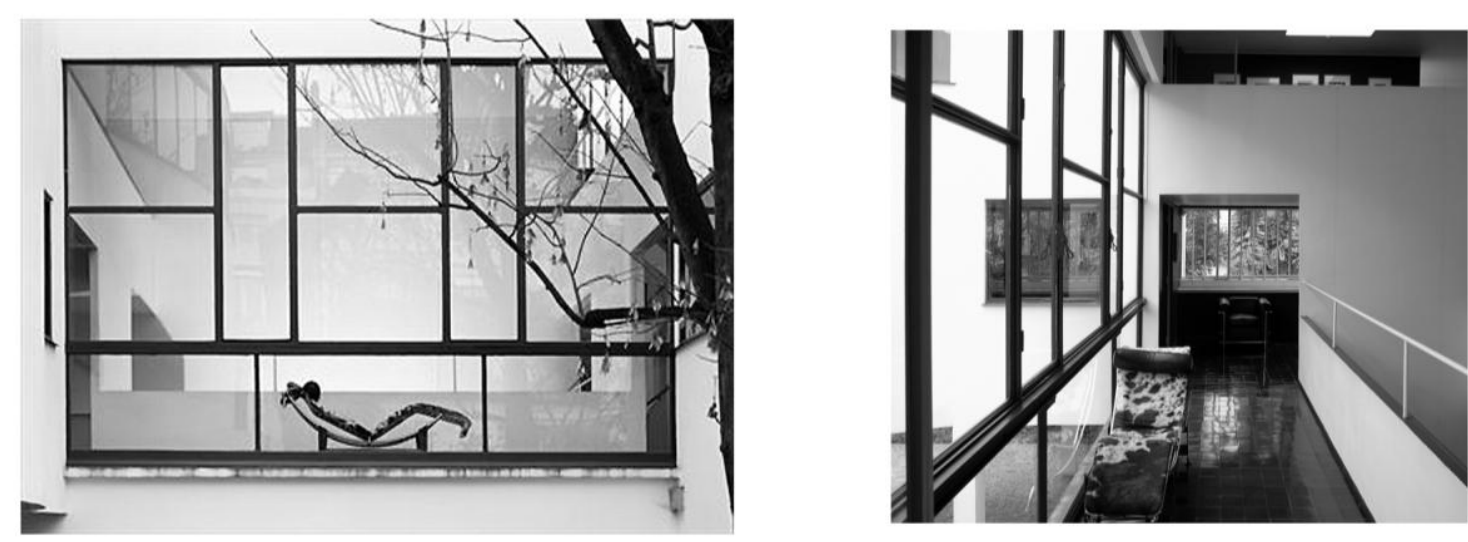

7. Casa La Roche-Jeanneret. Alzados. El ventanal desde el exterior y desde la pasarela.

Le Corbusier, nos ha dejado aquí un juego magnífico de relaciones entre los elementos que definen un espacio, y con ello abre la puerta a un sistema de composición por medio de planos que, aunque no afecta a la volumetría exterior del conjunto, anticipa futuros mecanismos de relación entre interior y exterior.

\subsection{Une Petite Maison}

Vamos a aproximarnos ahora a otro mecanismo fundamental en la definición de la relación entre interior y exterior, la fenêtre en longueur, y lo vamos a hacer partiendo de la casa que proyecta Le Corbusier para sus padres en el lago Léman casi al mismo tiempo que se construía la casa La Roche-Jeanneret. Comencemos por la propia descripción que hace Le Corbusier de la casa: “(...) de cara al Sur, se extiende a lo largo una vivienda de cuatro metros de profundidad, pero cuyo frente mide dieciséis metros. Su ventana tiene once metros de longitud, he dicho 'su'ventana (...) gracias a lo cual se accede a una vista incomparable e inalienable sobre uno de los mas bellos horizontes del mundo. (...) Entramos en la casa. ;La ventana de once metros le otorga categoría! Se trata de una innovación constructiva concebida para la posible función de una ventana: convertirse en el elemento, el actor principal de la casa",5.

\footnotetext{
${ }^{5}$ Jeanneret, Charles-Edouard (Le Corbusier): Una pequeña casa, Infinito, Buenos Aires, 2005.
} 
En los primeros dibujos y bocetos de la casa (FLC 09421 y FLC 09438) podemos observar ya la presencia de la larga ventana protagonizando la composición. La modulación presentada es idéntica a la definitiva, con cuatro partes independizadas por el ritmo de la estructura. Sin embargo, aquí la casa mantiene una relación más elevada con el lago y el desnivel se aprovecha para generar una especie de porche bajo la casa soportado por unos protopilotis. Las primeras versiones de la sección constructiva de la ventana presentan una carpintería en acero formada por un marco de perfil en L muy poco desarrollado (FLC 09362 y FLC 09363). La persiana en este caso queda alojada en una hornacina prevista en el interior de la casa, dejando el alzado sin sombra al exterior, y aunque ya se intuye la posición de la estructura esta todavía no tiene una solución definida. En la siguiente versión del alzado (FLC 09367) la planta inferior ha desaparecido y la casa ya queda colocada sobre el lago en una plataforma pero en un único nivel. Una sección constructiva por la ventana (FLC 09373) muestra claramente como un pequeño alero cubre el nicho en el cual queda alojada la persiana provocando una sombra sobre el alzado. La persiana queda vista desde el exterior de la casa, y el plano de la carpintería adelantado en el espesor de la solución pasa continuo por delante de los tubulares de estructura que ya empiezan a prever las placas de anclaje y transición con los elementos de hormigón. Esta solución mantiene la independencia de todas las partes que componen la solución, con cada una de ellas visualmente remarcada.
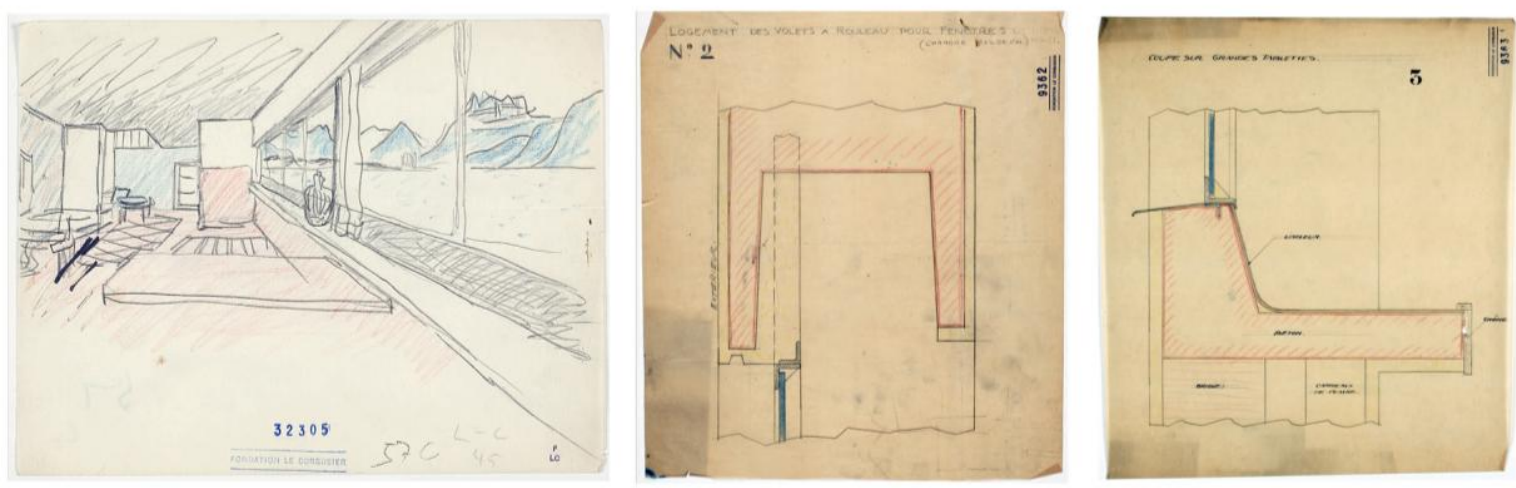

8. Villa Le Lac. Boceto FLC32305 y primeros detalles FLC 09362 y FLC 09363. OFLC-ADAGP

Como explica Le Corbusier, esta casa es una victoria de la ventana sobre el paisaje, sobre el horizonte. Es una victoria de la ventana sobre el espacio interior. La plus grande fenêtre en longueur sur la plus petite maison ${ }^{6}$. Aquí, además, la ventana supone un problema técnico a resolver, y se convierte por tanto en un mecanismo de proyecto, que en este caso lo articula absolutamente todo y se convierte a su vez en el único actor de la fachada.

La solución va a modificarse para la versión definitiva, la ventana recoge ahora en su parte superior externa el cajón de persiana que vuela sobre la fachada generando una sombra sobre el hueco (FLC 09385 y FLC09389), una solución similar pero menos pronunciada sobre la fachada valdrá para la "porte-fenêtre du petit salon", mientras que para el resto de huecos del alzado opuesto al lago se mantiene la solución del cajón hacia la cara interior del cerramiento (FLC09388). Argumenta Le Corbusier que todo está en fijar la altura del dintel y del alféizar; el problema de la estructura se resolverá por medio de esbeltos tubos de acero de $8 \mathrm{~cm}$. rellenos de hormigón. La estructura, en la versión definitiva, se integra en la carpintería de la fachada principal, no se independiza del resto de sistemas (FLC 09387).

\subsection{Villa Stein}

\footnotetext{
${ }^{6}$ Jeanneret, Charles-Edouard (Le Corbusier): Une Petite Maison 1923, Birkhauser, Switzerland, 2001.
} 
En 1925, aproximadamente al mismo tiempo que se terminaba la casa en el lago, Le Corbusier presenta su propuesta para la vivienda moderna en la exposición de París de aquel año, el pabellón del Esprit Nouveau. En él se recogen los planteamientos anteriores de sus Inmuebles Villa, propuesta que incorporaba el espacio exterior a las agrupaciones de vivienda en altura. Este concepto pensado originariamente para unos elementos agrupados, va a incorporarse casi de manera inmediata en la producción de viviendas unifamiliares de Le Corbusier, y supone un paso al frente en la combinación del mecanismo de terraza elevada presentado en la segunda versión de las casas Citrohan, y el mecanismo de gran riqueza espacial que vincula el interior y el exterior en el hall de la villa La Roche.

Su primera formalización con casi todas sus consecuencias se produce en la villa Stein en Garches del año 1927. Aquí se implementa la idea de la terraza exterior elevada como volumen substraído, como espacio contenido y delimitado que sirve de transición entre los espacios interiores domésticos y el mundo exterior. Este espacio queda definido por la construcción de las aristas del diedro, mientras se abre frontalmente hacia el jardín posterior, y parcialmente hacia arriba para conectar con el cielo. Sin embargo en esta ocasión aunque el espacio cumple todos los requisitos necesarios como mecanismo de transición y relación, las estancias interiores de la vivienda apenas si están abiertas al mismo mediante ventanas y puertas más o menos convencionales, desaprovechando la posibilidad de una transparencia transversal del espacio de la sala hacia él. Le Corbusier toma la decisión de potenciar la relación con el exterior del espacio principal de la casa de manera frontal mediante el mecanismo de fenêtre en longueur, que en este caso pliega en las esquinas la distancia justa para mostrar la separación exacta que está retrasada la estructura con respecto al plano de fachada. Se consigue así el efecto de que las láminas blancas opacas, tensas en horizontal, flotan sobre una abertura total que concede 180 grados de visión al habitante de la casa, y visto desde el exterior esta capacidad de dividir la masa del volumen va a tener consecuencias aún mayores en la percepción de conectividad espacial y transparencia.

Colin Rowe y Robert Slutzky presentan una lectura de este espacio desde el punto de vista complementario, infiriendo las propiedades de reconstrucción de la transparencia y la conexión fenomenológica más allá de la mera conexión física de los espacios: "although one can obviously see through his windows, it is not precisely here that the transparency of his building is to be found (...) Le Corbusier proposes the idea that immediately behind his glazing there lies a narrow slot of space travelling parallel to it; and of course, in consequence of this, he implies a further idea - that bounding this slot of space, and behind it, there lies a plane of which the ground floor, the freestanding walls, and the inner reveals of the doors all form a part; and although this plane may be dismissed as very obviously a conceptual convenience rather than a physical fact, its obtrusive presence is undeniable. Recognizing the physical plane of glass and concrete and this imaginary (though scarcely less real) plane that lies behind it, we become aware that here a transparency is effected not through the agency of a window but rather through our being made conscious of primary concepts which interpenetrate without optical destruction of each other" ${ }^{\prime \prime}$.

Van a ser estas aberturas, vistas desde el exterior y con ayuda de los restantes elementos de la composición volumétrica, las que obligan al espectador a deducir otra lectura de la condición del espacio interior. Todos estos efectos dependen en buena medida de la disposición y definición de los elementos de carpintería de las fenêtre en longueur. La especial preocupación por la definición de estas bandas de carpintería queda recogida en una serie de planos tanto de alzado exterior (FLC 10530) como de alzado interior y de planta (FLC 10484), y por supuesto de detalle (FLC 10462). Este cuidado en los encuentros entre carpintería y obra será una de las

\footnotetext{
${ }^{7}$ Rowe, Colin y Robert Slutzky: “Transparency: literal and phenomenal”, Perspecta no 8, 1964. Aquí extraído de: Rowe, Colin y Robert Slutzky, Transparency, Birkhäuser, Basel, 1997, pp. 36-37.
} 
preocupaciones constantes para la eliminación virtual de la presencia del límite en el espacio continuo, y como hemos podido observar, más allá de las consecuencias meramente físicas de la conectividad espacial, pueden lograr grandes efectos perceptuales y fenomenológicos que producen complejas sensaciones espaciales en el espectador.

9. Villa Stein. Alzado FLC 10530 y detalles de carpinterías FLC 10462. CFLC-ADAGP
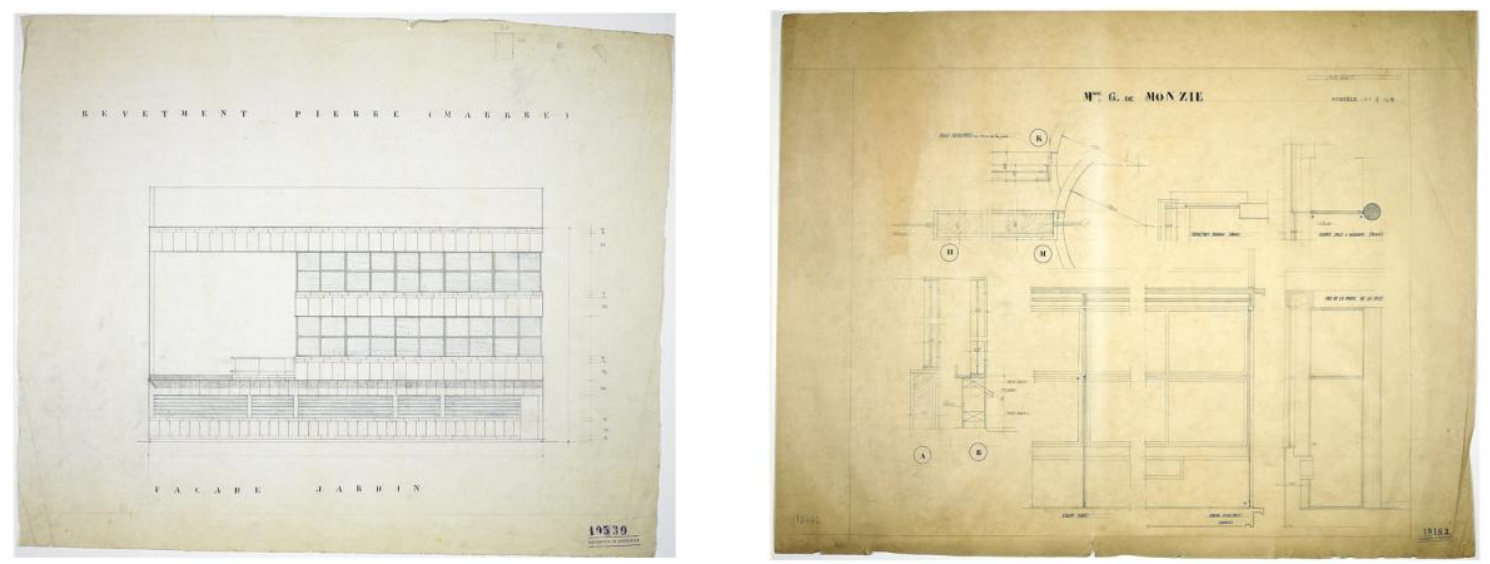

\subsection{Villa Savoye}

La decisión de hacer flotar los volúmenes va a tener otra consecuencia conceptual y formal, que tiene que ver con el reconocimiento mismo de esos cuerpos levantados como volúmenes puros, y no es otra que la imposibilidad de desvanecer completamente los límites exteriores. Le Corbusier escribe al respecto de la villa Savoye: "La casa es una caja en el aire, agujereada a su alrededor, sin interrupción, por una ventana en longitud. (...) Tomando vista y luz del contorno regular de la caja, las diferentes habitaciones van a juntarse, radiando, a un jardín suspendido, que se encuentra allí como si fuese un distribuidor de luz y de sol. Es el jardín suspendido sobre el cual se abren con toda libertad, las paredes correderas de cristales del salón y otras de las diferentes habitaciones de la casa: de esta manera el sol penetra por todas partes, llegando hasta el mismo corazón de la casa",

Le Corbusier puede plantearse interrupciones horizontales continuas en este objeto, pero dado que ha de reconocerse como volumen puro, no puede comunicar el espacio interior de manera completa y directa con el exterior a través de las fachadas. Entonces aplica aquí la solución del vaciado para generar una terraza, a modo de patio, que sea la extensión exterior del espacio principal de la casa. Como al levantarse ha perdido el contacto con el terreno y la naturaleza, convierte entonces la terraza en un jardín elevado. (FLC 19425)

Al disponer este espacio exterior perfectamente acondicionado, Le Corbusier puede abrir de manera franca y directa la sala al exterior, empleando para ello unas carpinterías deslizantes de gran formato que abarcan en altura desde el nivel continuo del pavimento hasta el propio plano interior del techo y, a lo ancho, la dimensión completa de la terraza. Una continuidad totalmente lograda que se va a prolongar hacia el territorio circundante mediante la incorporación completa del horizonte, visible a través de las rasgaduras horizontales que recorren las paredes limítrofes de la terraza.

\footnotetext{
${ }^{8}$ Jeanneret, Charles-Edouard (Le Corbusier): Precisiones, Apóstrofe, Barcelona, 1999, p. 158.
} 
Mientras que las carpinterías son "de acero en las viviendas de Pessac o la casa Ozenfant, las de la villa Savoye o la casa Stein son de madera y acero" (FLC 19480) más cuidadas en sus detalles y en los materiales empleados, sobre todo en lo que se refiere a la gran carpintería deslizante, elemento fundamental de conexión entre la sala y el jardín elevado.

En la primera versión de esta carpintería (FLC 19534) las secciones están constituidas exclusivamente por unos diminutos elementos metálicos, los espesores son casi inexistentes y la propuesta nos presenta unos vidrios que prácticamente se sujetan a ellos mismos. Es importante percibir el deseo de eliminar la presencia de la carpintería para ayudar a entender el concepto de disolución del límite. Esto mismo se remarca en este dibujo con la presencia de una pieza que recoge y esconde el atraque del vidrio fijo contra la pared en uno de los límites de la carpintería, así como la colocación de una U metálica con un listón de madera para recibir el vidrio deslizante. Este elemento a su vez queda emplazado en perpendicular y exterior a la pared, para lograr su desaparición visual desde el interior. Ya estaba presente, en dos pequeños bosquejos atravesados, el rodamiento superior y el mecanismo de polea mediante cadena, aunque aún no se describe la solución de su encuentro inferior. El perfil que recoge el mecanismo de la cadena parece estar sujeto directamente al soporte, ya que no aparecen los tubulares que lo sujetan. Tampoco hay rastro de la persiana exterior.

La segunda versión (FLC 19532) modifica los elementos de la carpintería dándoles un poco más de presencia. Probablemente el deseo colisionó aquí con la realidad constructiva y la necesidad de resolver los numerosos problemas inherentes a un elemento tan complejo como este. Se trata de un bosquejo realizado bastante rápido, y debió de ser un plano de transición hacia los siguientes. Puede verse una composición de perfiles en L y U de acero combinada con orlas, junquillos y otros elementos en madera. Están presentes los tubulares acodados que hacen de pies del elemento horizontal del mecanismo de cierre, y casi desde el principio se marca la presencia autónoma del pilar en los dibujos. Este hecho dará potencia a la realidad de objeto superpuesto a la fachada con la que se construye este mecanismo de cierre.
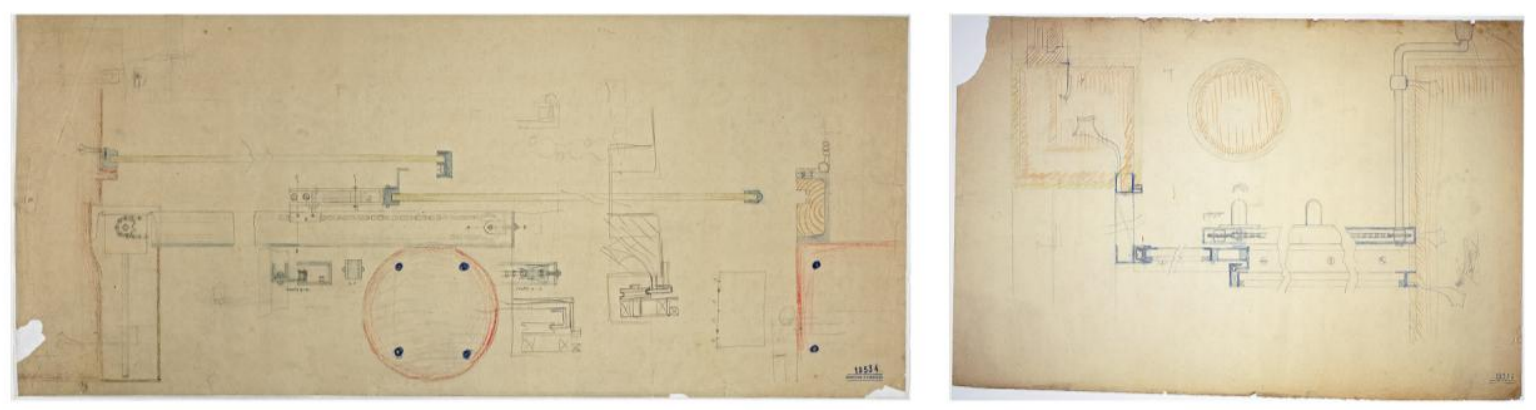

10. Villa Saboye. Detalles de carpinterías FLC 19534 y FLC19532. OFLC-ADAGP

La versión anterior se desarrolla en dos planos de corte vertical (FLC 19535) y horizontal (FLC 19637), en los que todos esos elementos se definen con un poco más de precisión. Cabe destacar la sustitución de la U metálica para la recogida de la hoja deslizante, por otro más complejo, que resuelve los problemas de aislamiento y condensaciones colocando un corcho entre dos chapas de acero. El junquillo que remata el conjunto en el vértice de la obra, contribuye a la desaparición visual del elemento. En la sección vertical vemos la preocupación por realizar un rehundido en la parte maciza de la obra, aunque esta no se encuentre todavía definida; esto se debe a la necesidad de ocultar a la vista todos los elementos del complejo mecanismo que hace funcionar al conjunto, y

\footnotetext{
${ }^{9}$ Torres Cueco, Jorge, Le Corbusier: visiones de la técnica en cinco tiempos, Fundación Caja de Arquitectos, Barcelona, 2004, p. 119.
} 
además aprovecha el rehundido para prever la colocación de las cortinas; el propio cerramiento de obra conforma un tacón que, actuando a modo de goterón, oculta la presencia de la carpintería también desde el exterior. Ya está planteado el sistema de recogida de agua bajo la hoja corredera, y su anclaje al suelo mediante la prolongación de la chapa de acero encajada en la ranura del canalón inferior.

En el siguiente plano (FLC 19502) se estudia por primera vez la incorporación del cajón metálico para resolver la persiana por el exterior, aunque en este caso enrasa con la fábrica por encima del dintel en su cara de fuera, con lo cual queda la duda de si no se tratará de un estudio posterior a los del proyecto de ejecución, e intermedio a la versión última dibujada.
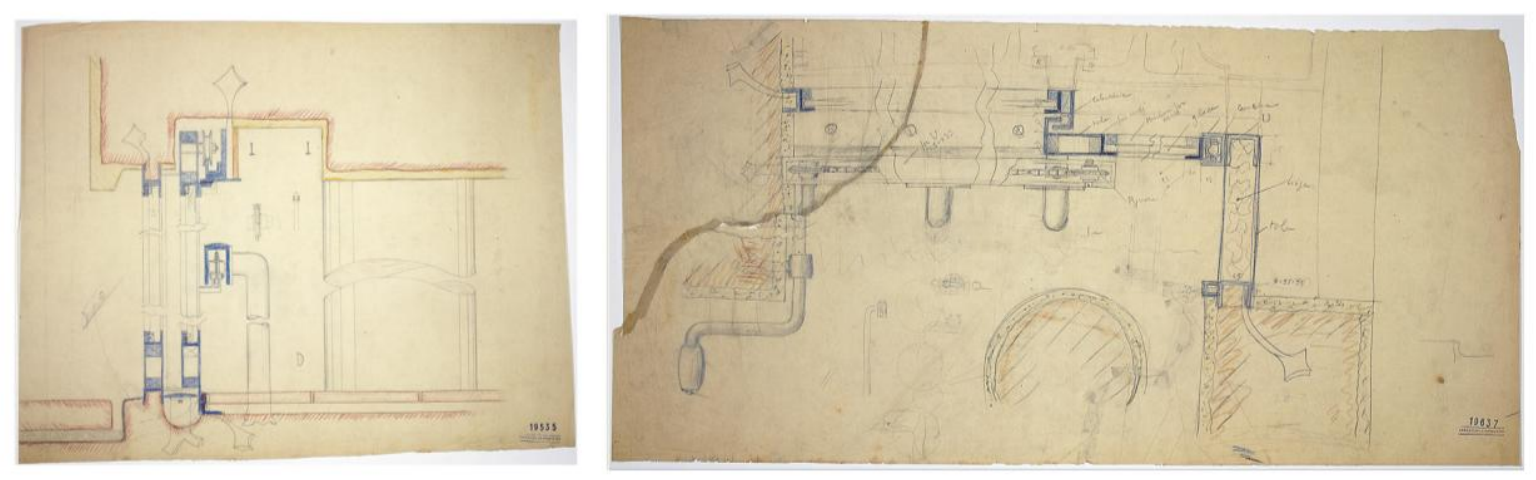

11. Villa Saboye. Detalles de carpinterías FLC 19535 y FLC19637. OFLC-ADAGP

Nos remitimos en este punto a las descripciones que hace Josep Quetglas en su libro sobre la villa Savoye: " $E l$ 11 de marzo, Burnham dibuja dos planos de detalle, "Savoye 2090" y "2091" (FLC 19437 y 19438), representando en sección, alzado y planta el mecanismo de deslizamiento y de la persiana de la cristalera de la gran sala, según una invención casi picabiana de Pierre Jeanneret. El bombo de la persiana se proyecta al exterior, en un medio cilindro envuelto en chapa metálica, al modo de las ventanas de la villa Baizeau. La luna deslizante es arrastrada por una cadena continua, movida manualmente con una manivela anclada a un pilar y protegida en una funda metálica que sirve también como barandilla frente a la luna fija" ${ }^{10}$.

Aquí el cajón de la persiana cobra ya todo el protagonismo desde el exterior, al tiempo que resuelve la visión del resto de elementos de la parte superior ocultándolos. La última versión dibujada va a simplificar más aún algunos aspectos.

"El 24 de mayo Frey vuelve a dibujar la sección de la cristalera corredera entre la sala y el jardín, en los planos "Savoye 2137" (FLC 19455) y "2138" (FLC 19456). (...) Por otro lado se simplifican también la carpintería de la cristalera y su mecanismo de deslizamiento, un poco en deterioro de la resistencia y a favor de una más neta definición de las líneas. Puede pensarse que se estiliza aquella manifestación directa del comportamiento de cada pieza, que había en la primera versión del mecanismo, donde se exhibían el manubrio, los ejes de rotación de la cadena y los apoyos de la funda-doblados en codo-, mientras que ahora no se demuestra ningún esfuerzo, sino que el mecanismo queda convertido en pura geometría. Sin duda se trata de un tránsito modélico, desde el gusto de Pierre Jeanneret hasta el de Le Corbusier. Durante la construcción acabará simplificando aún más

\footnotetext{
${ }^{10}$ Quetglas, Josep, Les Heures Claires: Proyecto y arquitectura en la villa Savoye de Le Corbusier y Pierre Jeanneret, Massilia, 2008, p. 212.
} 
este detalle, hasta no ser sino un perfil en $C$, con un sólo tubo metálico en el punto medio de su longitud, como ,11
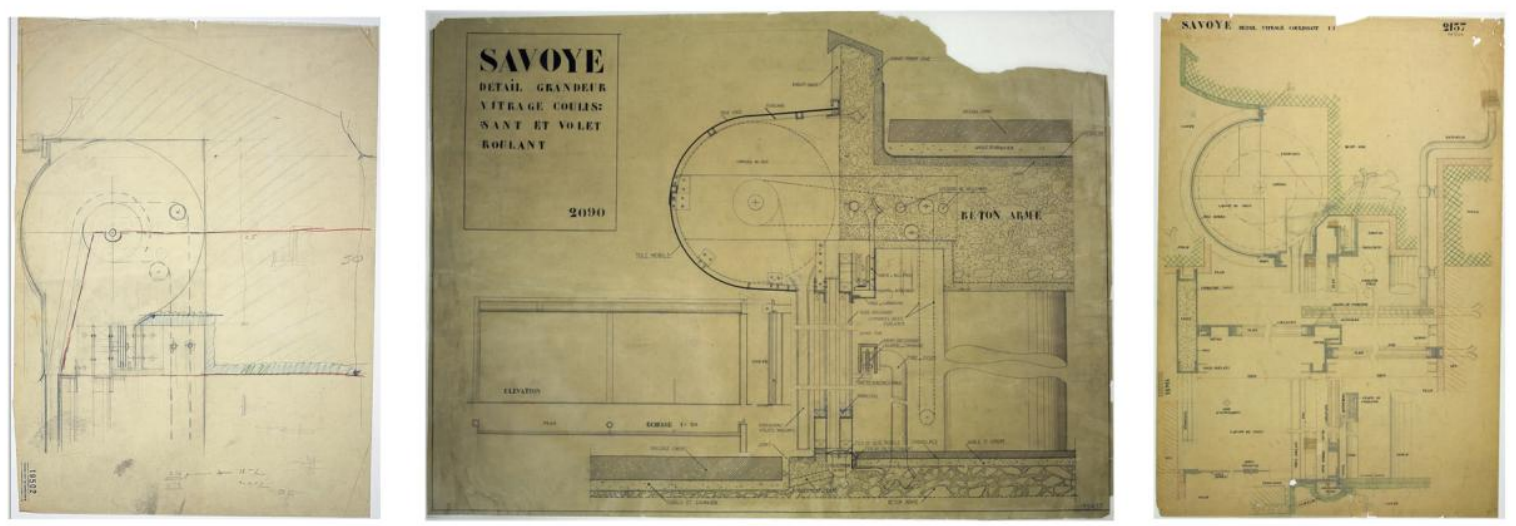

12. Villa Saboye. Detalles de carpinterías FLC 19502, FLC 19437 y FLC 19455. OFLC-ADAGP

Al final del viaje se imponen las tesis de ligereza visual del mecanismo, tal vez en detrimento del comportamiento general de la carpintería, no solo en cuanto a su resistencia sino también por las condensaciones. Este resulta un magnífico ejemplo de la tensión que existió entre lo visual y lo constructivo a lo largo del trayecto que estamos recorriendo, y es que la definición constructiva de los elementos de transición del espacio va a suponer una lucha permanente por alcanzar unos objetivos visuales más allá de los conceptuales.

\subsection{El pan de verre}

En la versión de los cinco puntos incluida en el número 10 de L'Architecture d'Aujourd'hui de 1933, nos encontramos con la substitución de la fenêtre en longueur por la ossature indépendante ${ }^{12}$. Este hecho no puede considerarse circunstancial, y como todo lo que hacia Le Corbusier está perfectamente meditado y direccionado para la consecución de unos objetivos. En primer lugar el concepto de estructura como sistema independiente es mucho más importante, y potente en sus consecuencias, que sus repercusiones en relación con el resto de sistemas recogidas en otros de los puntos. En segundo lugar, Le Corbusier comenzaba a ser consciente de las limitaciones de su propuesta de fenêtre en longueur, y de que ya existían arquitecturas que superaban el lenguaje visual asociado a la modernidad que trataba de representar la misma.

Todo esto dará lugar a la aparición de otro mecanismo que Le Corbusier incorporará a su arquitectura para la definición del límite del espacio, y que no es otro que el del pan de verre: "He construido muchísimas ventanas "en longitud"; mi atención se ha fijado en esos alféizares de ventana, las cuales no me parecen muy francas todavía (...) la ventana es el órgano más costoso de la casa. La ventana corriente es todo un montaje de hierro o de madera, es decir, algo infinitamente delicado, que requiere una construcción cuidada. ¿Y si pudiéramos, con un gesto, repudiar la ventana, pero dando, al mismo tiempo, luz a los pisos? (...) El examen de mi perfil-símbolo me muestra unas fachadas reducidas a algunas bandas de cemento de 30 centímetros de altura. (...) Vamos a sujetar a 25 centímetros por delante de estas bandas de cemento, por medio de cartelas de llanta, unos hierros verticales, bien colocados, que tengan aplomo. Y al través, fuera o dentro, unos hierros horizontales a unas distancias proporcionadas a los cristales o a los vidrios disponibles en el comercio. Por consiguiente, delante de

\footnotetext{
${ }^{11}$ Quetglas, Josep, Les Heures Claires: Proyecto y arquitectura en la villa Savoye de Le Corbusier y Pierre Jeanneret, Massilia, 2008, pp. 250-251.

${ }^{12}$ Lahuerta, Juan José, en el prólogo del libro: Roth, Alfred, Dos Casas de Le Corbusier y Perre Jeanneret, Colegio Oficial de Aparejadores y Arquitectos Técnicos, Murcia, 1997, pp. 9-10.
} 
las fachadas habrá un panel de vidrio. La fachada es un panel de cristal" ${ }^{\text {13 }}$. Vemos pues las dudas que finalmente le genera la fenêtre en longueur, y el reconocimiento parcial de que existe un mecanismo mejor, más rotundo, de expresar la separación entre los diferentes sistemas de la arquitectura. Este mecanismo del pan de verre va a estar presente tanto en obras de vivienda colectiva de Le Corbusier, como en bloques de edificios públicos. Desde el Immeuble Clarté hasta el Centrosoyus, pasando por los pabellones Suizo y Brasileño de la Ciudad Universitaria en Paris, las Unité d'Habitation o a proyectos tan significativos como el Immeuble des Invalides en la rue Fabert, el pan de verre va a configurar una manera de relacionarse con el paisaje y el territorio desde las posiciones elevadas de los bloques.

\subsection{Las maisons Jaoul}

Antes de cerrar este recorrido vamos a dar un salto temporal hasta las maisons Jaoul para ver brevemente un último mecanismo operativo sobre el límite del espacio evolucionado conceptualmente desde el pan de verre, que va a tener repercusión en numerosas arquitecturas: le pan de verre aménagé o le quatrième mur.

"Elle témoigne des recherches de Le Corbusier en matière de pan de verre aménagé. Le bois est ici étroitement associé au verre. et le vitrage est comme incornoré à l'ameublement" ${ }^{\prime 14}$.

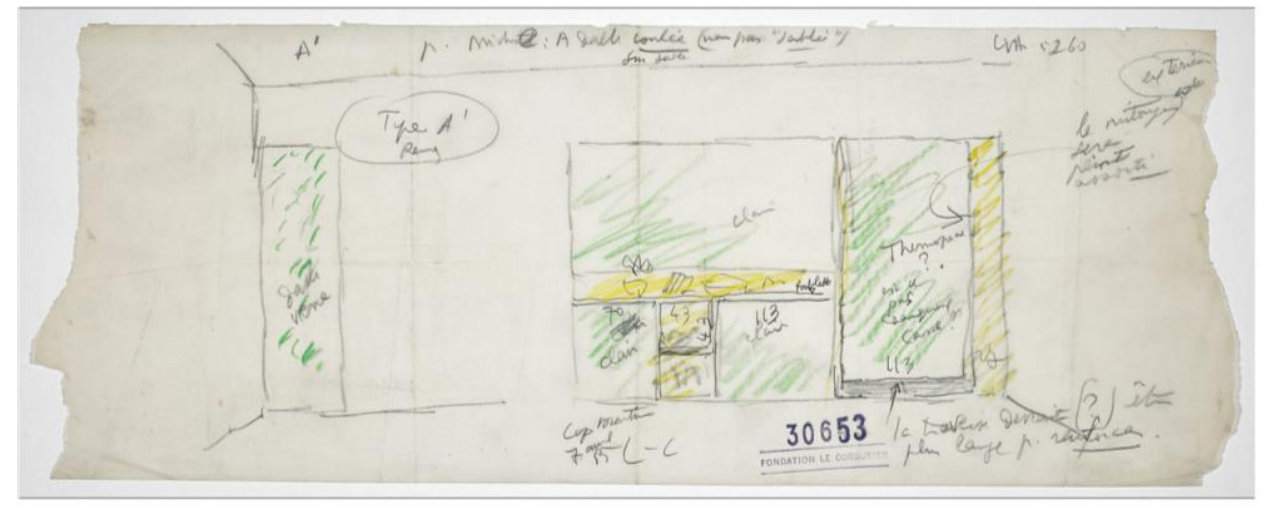

13. Maisons Jaoul. Boceto FLC 30653. CFLC-ADAGP

El paño de vidrio amueblado parece contradecir en sí mismo el principio del que parte. Delimitar el límite del espacio por una lámina transparente para después amueblarla y darle espesor retirándole la esencia misma de membrana resulta cuando menos desconcertante. Pudiera parecer que atribuir a ese mecanismo el nombre de cuarto muro acaba por revertir, semánticamente al menos, su asociación a la disolución del límite del espacio. Sin embargo las soluciones manejadas por Le Corbusier para estas casas y las cinco variables recogidas en el libro de Jules Alazard mantienen una distribución de los elementos opacos en el conjunto de la composición que permite seguir reconociendo el carácter de superposición de este pan de verre aménagé y la percepción de continuidad espacial por la continuidad de las aristas del volumen interior y de los planos que lo conforman. Los vidrios siempre liberan visualmente al menos tres de las esquinas del conjunto, y las partes opacas se componen de tal modo que parecen flotar como inserciones en el paño de vidrio. Le Corbusier habla de la liberación de los puntos estratégicos, de los muros laterales el suelo y el techo. De esa forma conceptualmente toma sentido la expresión de pan de verre aménagé puesto que realmente es el vidrio el que se amuebla y no los muebles los que reciben algunas partes transparentes.

\footnotetext{
${ }^{13}$ Jeanneret, Charles-Edouard (Le Corbusier), Precisiones, Apóstrofe, Barcelona, 1999, p 73.

${ }^{14}$ Alazard, Jules y Jean Pierre Hébert, De la fenetre au pan de verre dans l'oeuvre de Le Corbusier, Collection Actualité du verre $n^{\circ}$ 1, P.V.P. (Dunod), Paris, 1961.
} 
Como indica Caroline Maniaque, Le Corbusier va a retomar las observaciones de Alazard a propósito de la ventana en el Modulor 2: "Quelle évolution minutieuse, méticuleuse, continue de la fenêtre depuis vos articles de l'Esprit Nouveau de 1920 jusqu'à aujourd'hui! Les fenêtres "en longueur" nées de la construction industrielle de bois, de fer ou de béton armé, et des mesures du corps humain. Puis le "pan de verre" qui supprime la "retombée" coûteuse sous plafond ainsi que l'allège du sol; il apporte des ressources considérables à l'une des fonctions primordiales de la façade : éclairer. Puis au cours des années le pan de verre devient "le quatrième mur de la chambre"; il n'est pas totalement en verre; certains panneaux sont opaques; des bibliothèques s'y accrochent; des tables s'y appuient; il joue son rôle en éclairant des points stratégiques, les murs latéraux, le plafond et le sol. Puis, c'est le "brise soleil" qui jugule cet ennemi subitement né du pan de verre: l'ardeur solaire. [...] Le vitrage étant désormais à l'abri de la pluie, le bois peut reprendre la place du fer. À ce moment, la fenêtre de bois n'est plus faite d'un châssis à plat, mais de cadres posés "de champ". C'est une nouvelle esthétique de la fenêtre. La fenêtre passe au rang du mobilier, elle peut être architecturée pour elle-même, dedans et dehors..."

Más allá de la separación de los sistemas integrantes de la arquitectura, también las funciones asociadas a la ventana se disocian: aportar la luz y las vistas al exterior, airear y filtrar, prolongar el espacio y dar acceso a la terraza. Cada elemento que compone este nuevo muro de vidrio amueblado responde específicamente a una de esas funciones, y la ventana pasa a ser arquitectura en si misma al interior y al exterior.

Volviendo a las maisons Jaoul, podemos observar como en el alzado interior oeste de la maison B el dibujo de las sombras remarca esa profundidad ganada por el frente del espacio (FLC 09948). En el tramo derecho de la primera planta, la configuración de las zonas opacas parece excavar y recortar el paño de vidrio, dejando, como ya comentábamos anteriormente, tres de las esquinas del conjunto transparentes. De esta forma, las partes de madera parecen esculpirse autónomas en el espesor de la fachada. Esta versión realizada el 16 de abril de 1952 va a sufrir ciertas modificaciones cuando se dibuja nuevamente el 20 de noviembre, la composición de este paño en concreto ha variado ligeramente (FLC 09956). Un rayado rápido indica cuáles son las partes opacas del conjunto, y podemos observar un boceto esquemático de una persona sentada a la mesa asociada al conjunto. Desde el exterior, en los alzados realizados el 21 de noviembre de ese mismo año (FLC 09957) han desaparecido (o probablemente no están reflejados) los elementos ejecutados en madera de esa zona, mientras que en el resto de alzados han sido dibujados con todo el detalle de la veta grafiando el material.
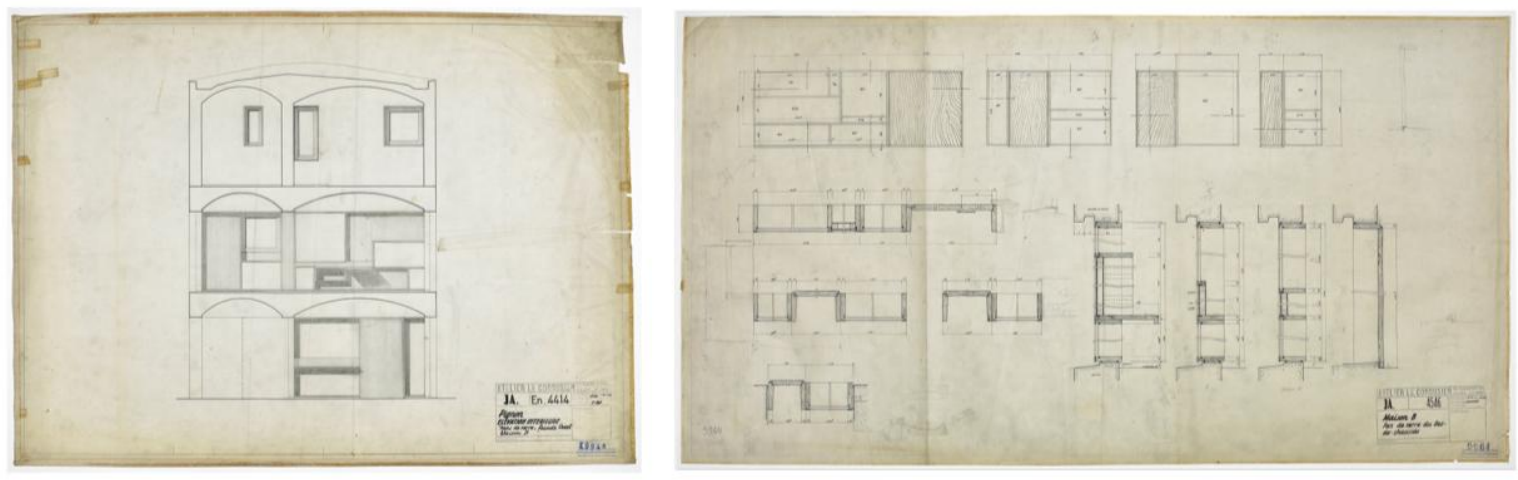

14. Maisons Jaoul. Alzado interior FLC 09948 y detalles de carpintería FLC 09964. @FLC-ADAGP

El plano de detalle de carpintería de los módulos de planta baja de esta casa (FLC 09964) nos muestra cómo se construye este límite espeso mediante unos costales de madera que conforman una profundidad de base de 20

\footnotetext{
${ }^{15}$ Maniaque, Caroline, Le Corbusier et les maisons Jaoul: projets et fabrique, Picard, Paris, 2005, p. 81.
} 
centímetros. Estos elementos van recibiendo alternativamente paños opacos que se abren para ventilar o vidrios dobles fijados mediante los junquillos exteriores. Este módulo crece en profundidad hacia el interior para poder conformar una estantería o prolongarse en una mesa de trabajo asociada al elemento de fachada. De alguna manera, Le Corbusier está logrando fusionar la idea del mobiliario asociado al límite del espacio para incrementar las relaciones entre interior y exterior. El pan de verre aménagé logra algo más que amueblar el límite del espacio, logra que el usuario lo habite y consecuentemente viva en ese lugar intermedio de relación entre el exterior y el interior de la vivienda, modificando una vez más la relación del habitante con el exterior y condicionando su mirada a través de un mecanismo evolucionado de la ventana.

\section{Conclusiones}

"La clé, c'est regarder: regarder, observer, voir, imaginer, inventer, créer""

A través de este recorrido podemos deducir que la manera de mirar, de entender la relación entre el interior y el exterior de la arquitectura estuvo permanentemente presente en la búsqueda del maestro suizo. Creador incansable, inventor de nuevas soluciones técnicas, capaz de imaginar nuevos caminos que anticipasen las necesidades formales, compositivas y, sobre todo vivenciales, de la nueva arquitectura. Le Corbusier transitó a lo largo de varias décadas desde la membrana, que disolvía la materialidad de los límites del espacio, hasta su materialización parcial mediante la incorporación de elementos de mobiliario. Durante el trayecto nos dejó ejemplos de cómo recuperar el horizonte incorporándolo al interior del espacio; también se ocupó de enmarcar la mirada en un juego simbólico de relaciones entre lugares que cobraban toda su intensidad por la mera aparición de un hueco ${ }^{17}$; o experimentó con el espesor de la piel para atrapar un espacio intermedio ${ }^{18}$ entre exterior e interior.

Los objetivos conceptuales a lo largo de cada una de las etapas y evoluciones de la ventana en la obra de Le Corbusier dependieron en gran medida de las soluciones técnicas y constructivas de los elementos. La esbeltez de las carpinterías, su configuración formal y compositiva, o la manera en la que se encuentran con los demás elementos constructivos han sido fundamentales para lograr los diferentes objetivos visuales. Las numerosas variaciones y estudios de los detalles constructivos de las ventanas presentes en los planos originales de las obras de Le Corbusier nos han dejado un testimonio fundamental del interés e importancia que la precisión de estos elementos tenía, y de cómo Le Corbusier era plenamente consciente de que solamente desde la experimentación y el avance técnico-constructivo podría alcanzar la depuración deseada.

Lamentablemente no todo cabe aquí. La longitud de este ensayo nos impide prolongar ciertas ideas que simplemente ha quedado enunciadas. Pero dejamos al lector interesado en profundizar en las relaciones apuntadas la tarea de descubrir observar, ver e imaginar más.

\section{Referencias bibliográficas}

Alazard, Jules y Jean Pierre Hébert, De la fenetre au pan de verre dans l'oeuvre de Le Corbusier, Collection Actualité du verre $n^{\circ}$ 1, P.V.P. (Dunod), Paris, 1961.

\footnotetext{
${ }^{16}$ Le Corbusier, Cap Martin, 1963.

17 Ver: Reichlin, Bruno: Dalla "soluzione elegante" all"'edificio aperto". Scritti attorno ad alcune opere di Le Corbusier, Mendrisio Academy Press / SilvanaEditoriale, Mendrisio, 2013, p. 95-97, 330-331.

${ }^{18}$ Ver: Merí de la Maza, Ricardo: "Le Corbusier: Flotando sobre el paisaje con una ventana infinita", en: La casa del principio del mundo. Mecanismos de disolución del límite del espacio en el norte de Portugal, Director: J.M. Moreno, Departamento de Proyectos Arquitectónicos, UPV, Valencia, 2012.
} 
Baudelaire, Charles: «Les fenêtres », Petits Poèmes en prose, édition posthume 1869.

Jeanneret, Charles-Edouard (Le Corbusier): Precisiones, Apóstrofe, Barcelona, 1999.

Jeanneret, Charles-Edouard (Le Corbusier): Una pequeña casa, Infinito, Buenos Aires, 2005.

Le Corbusier -Saugnier : Vers une architecture, Paris, éd. Crès, 1923.

Maniaque, Caroline, Le Corbusier et les maisons Jaoul: projets et fabrique, Picard, Paris, 2005.

Merí de la Maza, Ricardo: La casa del principio del mundo. Mecanismos de disolución del límite del espacio en el norte de Portugal, Director: J.M. Moreno, Departamento de Proyectos Arquitectónicos, UPV, Valencia, 2012.

Quetglas, Josep, Les Heures Claires: Proyecto y arquitectura en la villa Savoye de Le Corbusier y Pierre Jeanneret, Massilia, 2008.

Reichlin, Bruno: Dalla "soluzione elegante" all "'edificio aperto”. Scritti attorno ad alcune opere di Le Corbusier, Mendrisio Academy Press / SilvanaEditoriale, Mendrisio, 2013.

Roth, Alfred, Dos Casas de Le Corbusier y Perre Jeanneret, Colegio Oficial de Aparejadores y Arquitectos Técnicos, Murcia, 1997.

Rowe, Colin y Robert Slutzky, Transparency, Birkhäuser, Basel, 1997.

Rowe, Colin y Robert Slutzky: “Transparency: literal and phenomenal”, Perspecta no 8, 1964.

Torres Cueco, Jorge, Le Corbusier: visiones de la técnica en cinco tiempos, Fundación Caja de Arquitectos, Barcelona, 2004. 